\title{
Nurses' knowledge of universal health coverage for inclusive and sustainable elderly care services
}

\author{
Fabian Ling Ngai Tung ${ }^{1}$ \\ Vincent Chun Man Yan² \\ Winnie Ling Yin Tai ${ }^{3}$ \\ Jing Han Chen ${ }^{3}$ \\ Joanne Wai-yee Chung ${ }^{4}$ \\ Thomas Kwok Shing Wong ${ }^{5}$
}

\begin{abstract}
Objectives: to explore nurses' knowledge of universal health coverage (UHC) for inclusive and sustainable development of elderly care services. Method: this was a cross-sectional survey. A convenience sample of 326 currently practicing enrolled nurses (EN) or registered nurses (RN) was recruited. Respondents completed a questionnaire which was based on the implementation strategies advocated by the WHO Global Forum for Governmental Chief Nursing Officers and Midwives (GCNOMs). Questions covered the government initiative, healthcare financing policy, human resources policy, and the respondents' perception of importance and contribution of nurses in achieving UHC in elderly care services. Results: the knowledge of nurses about UHC in elderly care services was fairly satisfactory. Nurses in both clinical practice and management perceived themselves as having more contribution and importance than those in education. They were relatively indifferent to healthcare policy and politics. Conclusion: the survey uncovered a considerable knowledge gap in nurses' knowledge of UHC in elderly care services, and shed light on the need for nurses to be more attuned to healthcare policy. The educational curriculum for nurses should be strengthened to include studies in public policy and advocacy. Nurses can make a difference through their participation in the development and implementation of UHC in healthcare services.
\end{abstract}

Descriptors: Universal Coverage; Millennium Development Goals; Health Policy.

\footnotetext{
${ }^{1}$ Doctoral student, The Hong Kong Institute of Education, Hong Kong. Researcher, The Hong Kong Institute of Education, Hong Kong.

2 Doctoral student, The City University of Hong Kong, Hong Kong. Researcher, The Hong Kong Institute of Education, Hong Kong.

${ }^{3} \mathrm{PhD}$, Researcher, Ginger Knowledge Transfer and Consultancy Limited, Hong Kong.

${ }^{4}$ PhD, Full Professor, The Hong Kong Institute of Education, Hong Kong.

${ }^{5}$ PhD, Full Professor, Guangzhou University of Chinese Medicine, China.
}

Tung FLN, Yan VCM, Tai WLY, Chen JH, Chung JWY, Wong TKS. Nurses' knowledge of universal health coverage for inclusive and sustainable elderly care services. Rev. Latino-Am. Enfermagem. 2016;24:e2670. [Access 


\section{Introduction}

Universal health coverage (UHC) is defined as the entire spectrum of health services, ranging from health promotion, disease prevention, acute care and treatment, rehabilitation, to palliative care, and it should be financially affordable and geographically accessible to everyone in need ${ }^{(1)}$. The definition embraces two key concepts: inclusiveness of the coverage and the sustainable development of the services provided.

Despite many political and resource constraints, the initiatives for UHC have been reinforced again in 2000, in many countries, since the establishment of Millennium Development Goals (MDGs) following the United Nations Millennium Summit(1). One hundred and ninety-one United Nations members have committed to achieve the MDGs by 2015 . In response to the MDGs, the WHO Global Forum for Governmental Chief Nursing Officers and Midwives (GCNOMs) has declared a commitment to develop a competent nursing workforce at all levels of healthcare delivery systems to support the initiatives for $\mathrm{UHC}^{(2)}$. A set of implementation strategies was subsequently recommended for countries to follow. To succeed, it requires the contribution of nurses who are involved in policy making, management, education and clinical service.

The WHO has been advocating UHC over the past few decades to ensure all human beings are able to seek health services and are not deprived of services because of financial hardship(3). The elderly population is one of the most vulnerable groups that require extra effort in order to achieve UHC. This is partly because of the loss of gainful employment and partly because of the increased incidence of co-morbidity in this group of people. As expected, demands for health and social care will increase by many folds due to the trending rise in the aging population. Thus, the rights of elderly in accessing healthcare may face unprecedented levels of threat; Hong Kong is no exception(4). In Hong Kong, the healthcare system, including elderly services, relies on both public sector and private sector. While $88 \%$ of the secondary and tertiary healthcare services were provided by the public sector, nearly $70 \%$ of the primary healthcare services were provided by the private sector $^{(5)}$. All Hong Kong citizens are eligible to seek medical services from the public sector at a very low fee. This fee may also be waived if the person covered by the comprehensive social security scheme (CSSA).

The development of the nursing profession in Hong Kong is considered relatively more mature than in many Asian countries, yet the level of nurses' participation in politics was reported to be $\operatorname{low}^{(6)}$. More often than not, nurses were perceived to be apathetic to political decisions, even if they were healthcare related(7). Heavy workloads, a sense of powerlessness, gender bias, lack of understanding of the political and policy making process, and ethical conflicts between professional and political values may account for this. Nurses, as one of the major healthcare providers, are the key members in the provision of quality healthcare services, and advocate for health choices and health policies ${ }^{(8-9)}$. It is important for them to be knowledgeable of the implementation strategies for UHC, even if they do not fully understand.

Healthcare services for elderly in Hong Kong are far from adequate, despite many new initiatives have been implemented(10-12). Many institutions, such as day centers, skilled nursing facilities and infirmaries want to support the initiatives; however, they cannot find enough nurses to do so. The goal of achieving UHC for elderly healthcare services is moving farther away. The situation does not appear to have any impact on nurses. This is rather unusual, as nurses have been very devoted to vulnerable people in Hong Kong. Hence, the research team decided to look into the fundamental problem that leads to this phenomenon. Are nurses aware of these initiatives which were purposely developed to support UHC for elderly healthcare services in Hong Kong?

The UHC movement was first initiated in 1941. Over the last few decades, the focus of the movement has been reviewed and changed, for example, from poverty to gender equality, and to child welfare. However, the impact of UHC is yet to be seen. Engagement of various agencies, government officials, political leaders and relevant stakeholders is crucial in the course of implementation(13). For engagement to succeed, knowledge of every party is crucial. To understand this, the research team designed this study to explore nurses' knowledge of Universal Health Coverage (UHC) for inclusive and sustainable development of elderly care services in Hong Kong.

\section{Method}

A cross-sectional survey was conducted in May and June of 2015, after ethical clearance was approved by The Hong Kong Institute of Education. A list of potential respondents was generated from a pool of nurses who had experience interacting with some members of the research team. One researcher then called the respondents to explain the purpose of the call and the details of the study. He also checked their eligibility. Having obtained their consent to participate, the research team sent an information sheet and a questionnaire to the respondents electronically. Email reminders were sent to them two and four weeks after 
the initial distribution of the questionnaire. Names were not collected, to ensure anonymity.

To ensure ecological validity, the research team developed a demographic profile sheet and 17 questions initially based on the implementation strategies recommended by the WHO Global Forum for the Governmental Chief Nursing Officers and Midwives (GCNOMs). Three research team members who were not involved in the development of the questionnaire served as experts to independently review the relevancy of the draft questions. Four questions were removed and several required further elaboration by adding sub-questions to the original questions.

Apart from the demographic profile, there were two parts in the final version of the questionnaire, namely, knowledge of inclusiveness of UHC and the perceived contribution to sustainable development of
UHC (Figure 1). Inclusiveness of UHC was composed of the government initiative (Q1), healthcare financing policy (Q2, 3, 4, 5 and 6), and human resources policy (Q7, 8, 9, 10 and 11). Respondents were asked to indicate their level of knowledge of UHC. For sustainable development of UHC, respondents were asked to rate their perceived contribution (Q12) and perceived importance of nurses (Q13). Split half reliability was performed using Spearman's coefficient which was satisfactory at 0.881 . With the unique function of the e-questionnaire system, the respondents' answers were automatically compiled in a table format. Descriptive and inferential statistics were then computed and a comparison was performed by years of experience, job title, nature of one's role, and their qualifications.

Survey on nurses' knowledge of universal health coverage (UHC) for inclusive and sustainable elderly care services in Hong Kong

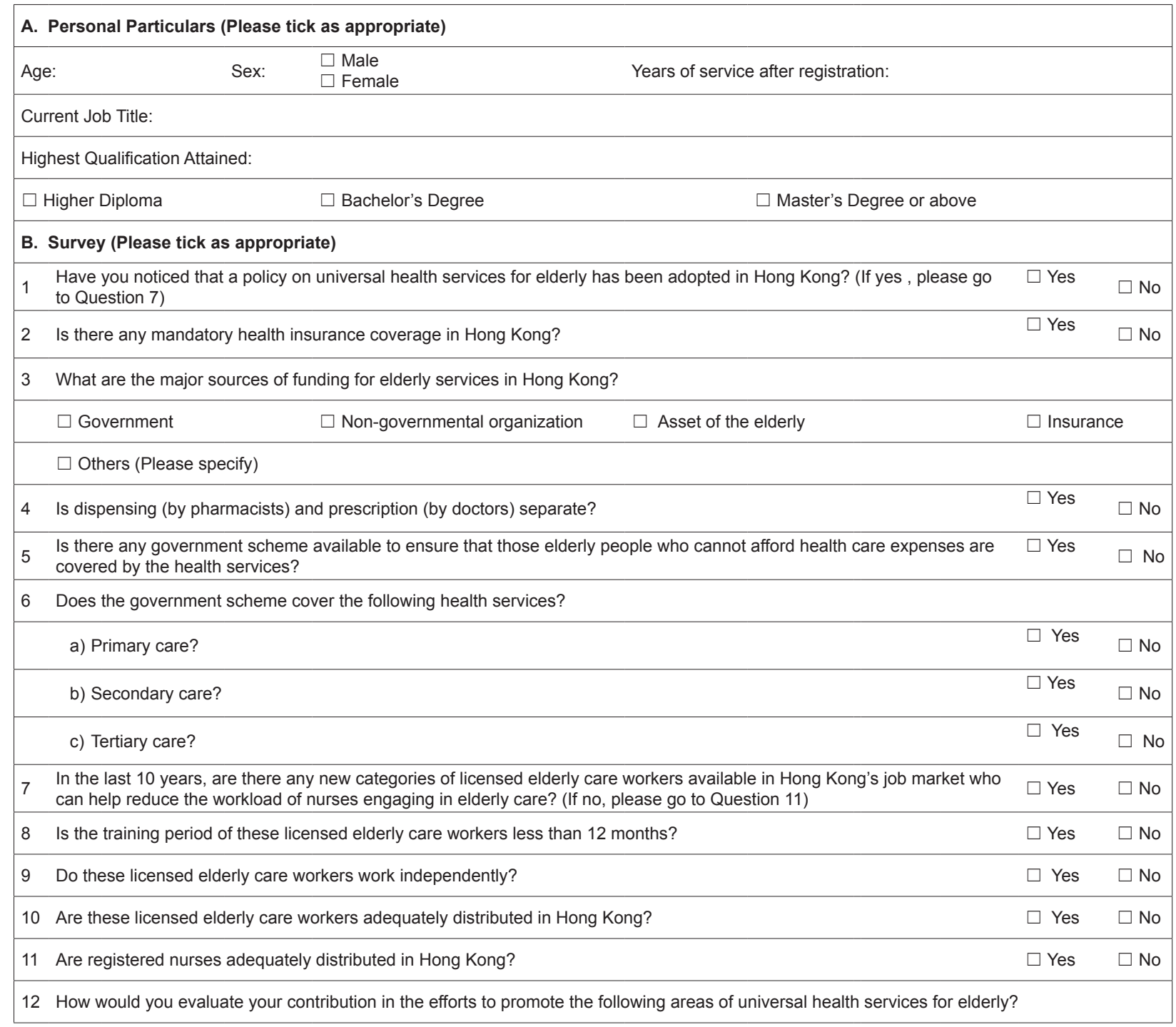




\begin{tabular}{|c|c|c|c|c|c|c|c|}
\hline & & & \multicolumn{5}{|c|}{ Extent of Contribution } \\
\hline & & & $<20 \%$ & $20-39 \%$ & $40-59 \%$ & $60-79 \%$ & $\geq 80 \%$ \\
\hline \multicolumn{3}{|c|}{$\begin{array}{l}\text { a) To ensure the continuity of the health care system, you have lobbied pressure } \\
\text { groups for support. }\end{array}$} & $\square$ & $\square$ & $\square$ & $\square$ & $\square$ \\
\hline \multicolumn{8}{|c|}{ b) You have helped formulate nursing policies for the provision of } \\
\hline \multicolumn{3}{|c|}{ d) integrated services } & $\square$ & $\square$ & $\square$ & $\square$ & $\square$ \\
\hline \multicolumn{3}{|r|}{ i. people-oriented services } & $\square$ & $\square$ & $\square$ & $\square$ & $\square$ \\
\hline \multicolumn{3}{|c|}{$\begin{array}{l}\text { c) You have helped develop/strengthen policies to improve the quality of nursing } \\
\text { education or training. }\end{array}$} & $\square$ & $\square$ & $\square$ & $\square$ & $\square$ \\
\hline \multicolumn{8}{|c|}{ d) You have helped amended existing policies for the } \\
\hline & i. & recruitment of new staff & $\square$ & $\square$ & $\square$ & $\square$ & $\square$ \\
\hline & ii. & retention of staff & $\square$ & $\square$ & $\square$ & $\square$ & $\square$ \\
\hline & iii. & i. deployment of manpower & $\square$ & $\square$ & $\square$ & $\square$ & $\square$ \\
\hline \multicolumn{3}{|c|}{$\begin{array}{l}\text { e) You have helped develop an evidence-based policy that is effective and efficient in } \\
\text { managing the nursing workforce. }\end{array}$} & $\square$ & $\square$ & $\square$ & $\square$ & $\square$ \\
\hline \multicolumn{8}{|c|}{$\begin{array}{l}\text { f) You have helped support educational institutions to develop/implement training } \\
\text { programs to meet }\end{array}$} \\
\hline & i. & the constantly changing quantitative demand of health care needs & $\square$ & $\square$ & $\square$ & $\square$ & $\square$ \\
\hline & ii. & i. the constantly changing qualitative demand of health care needs. & $\square$ & $\square$ & $\square$ & $\square$ & $\square$ \\
\hline & iii. & i. the constantly changing qualitative demand of health care needs. & $\square$ & $\square$ & $\square$ & $\square$ & $\square$ \\
\hline \multicolumn{3}{|r|}{$\begin{array}{l}\text { g) You have helped upgrade relevant professional skills to provide high-quality nursing } \\
\text { education }\end{array}$} & $\square$ & $\square$ & $\square$ & $\square$ & $\square$ \\
\hline \multicolumn{3}{|c|}{$\begin{array}{l}\text { h) You have helped assess the gap between the actual supply and demand of health } \\
\text { care services }\end{array}$} & $\square$ & $\square$ & $\square$ & $\square$ & $\square$ \\
\hline \multicolumn{3}{|r|}{ You have helped develop effective strategies to narrow such a gap } & $\square$ & $\square$ & $\square$ & $\square$ & $\square$ \\
\hline & j) & $\begin{array}{l}\text { You have helped develop effective strategies or plans with working partners } \\
\text { to improve health care services. }\end{array}$ & $\square$ & $\square$ & $\square$ & $\square$ & $\square$ \\
\hline \multicolumn{8}{|c|}{$\begin{array}{l}\text { How would you evaluate the importance of contribution of nurses in Hong Kong to the universal health services for elderly? } \\
\text { 1=very important; } 2=\text { =important; } 3=\text { somewhat important; } 4=\text { not important }\end{array}$} \\
\hline & & & & \multicolumn{4}{|c|}{ Level of importance } \\
\hline & & & & 1 & 2 & 3 & 4 \\
\hline & a) & $\begin{array}{l}\text { To ensure the continuity of the health care system, they have lobbied pressur } \\
\text { support. }\end{array}$ & oups for & $\square$ & $\square$ & $\square$ & $\square$ \\
\hline \multicolumn{8}{|c|}{ b) They have helped formulate nursing policies to provide } \\
\hline & i. & i. integrated services & & $\square$ & $\square$ & $\square$ & $\square$ \\
\hline & ii. & i. people-oriented services & & $\square$ & $\square$ & $\square$ & $\square$ \\
\hline & c) & $\begin{array}{l}\text { They have helped develop or strengthen policies to improve the quality of nur } \\
\text { education or training }\end{array}$ & & $\square$ & $\square$ & $\square$ & $\square$ \\
\hline \multicolumn{8}{|c|}{ d) They have amended existing policies for the } \\
\hline & i. & i. recruitment of new staff & & $\square$ & $\square$ & $\square$ & $\square$ \\
\hline & ii. & i. retention of staff & & $\square$ & $\square$ & $\square$ & $\square$ \\
\hline & iii. & i. deployment of manpower & & $\square$ & $\square$ & $\square$ & $\square$ \\
\hline & $\begin{array}{l}\text { e) They he } \\
\text { nursing }\end{array}$ & $\begin{array}{l}\text { have helped develop an evidence-based policy that is effective and efficient to } \\
g \text { workforce. }\end{array}$ & nage the & $\square$ & $\square$ & $\square$ & $\square$ \\
\hline \multicolumn{8}{|c|}{$\begin{array}{l}\text { f) They have helped support educational institutions in developing/ implementing training programs } \\
\text { to meet }\end{array}$} \\
\hline & i. & The constantly changing quantitative demand of health care needs & & $\square$ & $\square$ & $\square$ & $\square$ \\
\hline & ii. & The constantly changing qualitative demand of health care needs. & & $\square$ & $\square$ & $\square$ & $\square$ \\
\hline \multicolumn{4}{|c|}{ g) They have helped upgrade relevant professional skills to provide high-quality nursing education } & $\square$ & $\square$ & $\square$ & $\square$ \\
\hline \multicolumn{4}{|c|}{ h) They have helped assess the gap between the actual supply and demand of health care services } & $\square$ & $\square$ & $\square$ & $\square$ \\
\hline \multicolumn{4}{|c|}{ i) They have helped develop effective strategies to narrow such a gap } & $\square$ & $\square$ & $\square$ & $\square$ \\
\hline \multicolumn{4}{|c|}{$\begin{array}{l}\text { j) They have helped develop effective strategies or plans with working partners to improve the } \\
\text { utilization of health care services. }\end{array}$} & $\square$ & $\square$ & $\square$ & $\square$ \\
\hline
\end{tabular}


End of questionnaire

Thank you

Figure 1 - Survey on nurses' knowledge of universal health coverage (UHC) for inclusive and sustainable elderly care services in Hong Kong

\section{Results}

Of the 326 recruited respondents, about $75.8 \%$ were female $(n=247)$ and $24.4 \%$ were male $(n=79)$. The sample size provided reasonable protection against Type II error, given a minimum $5 \%$ of precision with $5.41 \%$ of alpha error, whereas the confidence interval was $95 \%$.

\section{Demographic characteristics}

Table 1 shows the demographic characteristics of the respondents. The ratio between registered nurse and enrolled nurse (RN/EN) was comparable to that of the proportional distribution in Hong Kong(14). The majority of them were young (aged 35 or below), baccalaureate prepared, and working in clinical settings.

Table 1 - Demographic distribution of respondents $(N=326)$. Hong Kong, 2015

\begin{tabular}{|c|c|c|}
\hline Variables & $\mathrm{n}$ & $\%$ \\
\hline \multicolumn{3}{|l|}{ Gender $(N=326)$} \\
\hline Female & 247 & 75.8 \\
\hline Male & 79 & 24.2 \\
\hline \multicolumn{3}{|l|}{ Age Group $(\mathrm{N}=320)$} \\
\hline$\leqq 20$ & 3 & 0.9 \\
\hline $21-25$ & 91 & 28.4 \\
\hline $26-30$ & 76 & 23.8 \\
\hline $31-35$ & 76 & 23.8 \\
\hline $36-40$ & 22 & 6.9 \\
\hline$\geqq 41$ & 52 & 16.3 \\
\hline \multicolumn{3}{|l|}{ Post-registration Year $(\mathrm{N}=326)$} \\
\hline $1-5$ & 171 & 52.5 \\
\hline $6-10$ & 76 & 23.3 \\
\hline$\geqq 11$ & 79 & 24.2 \\
\hline \multicolumn{3}{|l|}{ Current Job Title $(\mathrm{N}=326)$} \\
\hline Enrolled Nurse (EN) & 73 & 22.4 \\
\hline Registered Nurse (RN) & 192 & 58.9 \\
\hline Senior Clinician (RN) & 16 & 4.9 \\
\hline Management (RN) & 26 & 8.0 \\
\hline Education (RN) & 19 & 5.8 \\
\hline \multicolumn{3}{|l|}{ Nature of Role $(\mathrm{N}=326)$} \\
\hline Clinician & 269 & 82.5 \\
\hline Management & 39 & 12.0 \\
\hline Education & 18 & 5.5 \\
\hline \multicolumn{3}{|l|}{ Highest Qualification ( $\mathrm{N}=326$ ) } \\
\hline Higher Diploma & 88 & 27.0 \\
\hline Bachelor's Degree & 136 & 41.7 \\
\hline Master's Degree or Higher & 102 & 31.3 \\
\hline
\end{tabular}

*Percentage may not add up to 100 because some respondents declined to answer the questions.

Inclusiveness of UHC for elderly healthcare services:

\section{Governmental initiative}

The results showed that slightly more than half of the respondents $(171,52.5 \%)$ were unaware of the implementation of UHC in Hong Kong. No statistical significances were reported by years of experience, job title, nature of role, or qualification.
Inclusiveness of UHC for elderly healthcare services: Healthcare financing policy

Two hundred and eighty-eight (88.3\%) respondents correctly answered that there was no mandatory health insurance coverage in Hong Kong. Significant statistical differences were detected between nurses with a Higher Diploma (HD) and nurses with a master's degree 
$(p=0.005)$. More nurses with HD responded incorrectly that there was mandatory health insurance coverage in Hong Kong than nurses with a master's degree. These respondents $(n=288)$ were asked to indicate their knowledge of the healthcare financing issues in questions 2 to 6 (Table 2) which covered the inclusiveness of UHC for elderly healthcare services.

Table 2 - Percentage of responses in healthcare financing. Hong Kong, 2015

\begin{tabular}{|c|c|c|c|c|c|c|c|c|c|c|c|c|c|c|c|}
\hline \multirow{2}{*}{ Question } & \multicolumn{4}{|c|}{ By years of experience (\%) } & \multicolumn{3}{|c|}{ By job title (\%) } & \multicolumn{4}{|c|}{ By nature of role (\%) } & \multicolumn{4}{|c|}{ By qualification (\%) } \\
\hline & $1-5$ & $6-10$ & $>10$ & Sig. & EN & RN & Sig. & C & M & $E$ & Sig. & H & B & M & Sig. \\
\hline 2 & 86.5 & 90.8 & 89.9 & NS & 80.8 & 90.6 & NS & 87.7 & 94.9 & 83.3 & NS & 80.7 & 89.0 & 94.1 & 0.015 \\
\hline 3 & 83.8 & 84.1 & 80.3 & NS & 84.7 & 82.8 & NS & 83.5 & 81.1 & 80.0 & NS & 80.3 & 89.3 & 77.1 & NS \\
\hline 4 & 23.0 & 36.2 & 63.4 & $<0.001$ & 25.4 & 30.5 & $<0.001$ & 29.2 & 70.3 & 60.0 & $<0.001$ & 19.7 & 28.9 & 57.3 & $<0.001$ \\
\hline 5 & 56.1 & 60.9 & 64.3 & NS & 49.2 & 58.6 & NS & 56.4 & 72.2 & 73.3 & NS & 53.5 & 62.8 & 58.9 & NS \\
\hline $6 a$ & 7.2 & 11.9 & 19.6 & NS & 10.3 & 9.8 & NS & 9.8 & 14.8 & 27.3 & NS & 10.5 & 5.3 & 21.1 & 0.019 \\
\hline $6 b$ & 72.3 & 66.7 & 84.8 & NS & 65.5 & 72.5 & NS & 71.4 & 85.2 & 81.8 & NS & 68.4 & 71.1 & 82.5 & NS \\
\hline $6 c$ & 48.2 & 54.8 & 73.9 & 0.018 & 51.7 & 50.0 & 0.050 & 51.1 & 74.1 & 81.8 & 0.020 & 50.0 & 48.7 & 71.9 & 0.018 \\
\hline
\end{tabular}

*Percentage only includes affirmative responses

$+\mathrm{NS}=$ Not significant

$\neq B y$ nature of role: $C=$ Clinician, $M=$ Management and $E=$ Education

§By qualification: $\mathrm{H}=$ Higher Diploma, $\mathrm{B}=$ Bachelor's degree, and $\mathrm{M}=$ Master's degree or higher

$\|$ Only those who answered 'No' to 2 were required to answer $3,4,5,6 a, 6 b$ and $6 c$

About two-thirds of the participants indicated that dispensing and prescribing were separate systems (Q4), which was wrong. Forty percent of respondents incorrectly indicated that the government did not cover elderly who could not afford health services (Q5) and tertiary care (Q6c). In Hong Kong, the Government was not the major provider for primary care (Q6a), however, $88.3 \%$ thought it was.

\section{Inclusiveness of UHC for elderly healthcare services: Human resource policy}

Enrolled Nurses (ENs) showed significantly higher level of knowledge of the presence of the new categories of licensed elderly care workers in Hong Kong than the RNs, while those with a HD had significantly better knowledge of the training period (Table 3 ). This is reasonable because ENs were mostly HD holders while RNs held degrees. It may also reflect the reality that many ENs work in the elderly care sector, where many care providers belong to the new category of licensed elderly care workers.

Table 3 - Percentage of responses in human resources policy. Hong Kong, 2015

\begin{tabular}{|c|c|c|c|c|c|c|c|c|c|c|c|c|c|c|c|}
\hline \multirow{2}{*}{ Question } & \multicolumn{4}{|c|}{ By years of experience (\%) } & \multicolumn{3}{|c|}{ By job title (\%) } & \multicolumn{4}{|c|}{ By nature of role(\%) } & \multicolumn{4}{|c|}{ By qualification (\%) } \\
\hline & $1-5$ & $6-10$ & $>10$ & Sig. & EN & RN & Sig. & C & M & E & Sig. & $\mathbf{H}$ & B & M & Sig. \\
\hline 7 & 57.3 & 50.0 & 50.6 & NS & 63.0 & 51.6 & 0.047 & 54.6 & 48.7 & 55.6 & NS & 56.8 & 55.9 & 49.0 & NS \\
\hline 8 & 86.7 & 78.9 & 89.7 & NS & 91.3 & 82.8 & NS & 85.7 & 84.2 & 88.9 & NS & 96.0 & 82.9 & 79.6 & 0.043 \\
\hline 9 & 36.7 & 34.2 & 41.0 & NS & 43.5 & 35.4 & NS & 38.1 & 36.8 & 22.2 & NS & 42.0 & 34.2 & 36.7 & NS \\
\hline 10 & 74.5 & 73.7 & 84.6 & NS & 67.4 & 78.8 & NS & 74.8 & 88.9 & 84.2 & NS & 70.0 & 73.7 & 87.8 & NS \\
\hline 11 & 19.9 & 19.7 & 14.1 & NS & 17.8 & 19.8 & NS & 19.0 & 17.9 & 11.8 & NS & 15.9 & 20.6 & 17.8 & NS \\
\hline
\end{tabular}

*Percentage only includes affirmative responses

$+\mathrm{NS}=$ Not significant

\#By nature of role: $\mathrm{C}=$ Clinician, $\mathrm{M}=$ Management and $\mathrm{E}=$ Education

§By qualification: $\mathrm{H}=$ Higher Diploma, $\mathrm{B}=$ Bachelor's degree, and $\mathrm{M}=$ Master's degree or higher

IOnly those who answered 'Yes' to 7 were required to answer 8, 9 and 10

\section{Sustainable development of UHC for elderly healthcare services: Perceived contribution}

Question 12 asked the respondents to evaluate the extent of their contribution in the efforts to promote UHC for elderly healthcare services (Figure 1). For the purpose of data analysis, the research team considered the respondent's rating of $40 \%$ or higher as 'having positive contribution'. Table 4 showed that those with six to ten years of experience, RNs and those with a master's degree or higher perceived themselves to have significantly less contribution in formulating nursing policies for the provision of integrated care, peopleorientated care, amendments to existing policies for recruitment of new staff, and supporting educational institutions to develop/implement training programs to meet the societal needs qualitatively. 
Table 4 - Percentage of responses in perceived contribution to UHC for elderly healthcare services. Hong Kong, 2015

\begin{tabular}{|c|c|c|c|c|c|c|c|c|c|c|c|c|c|c|c|}
\hline \multirow{2}{*}{ Question } & \multicolumn{4}{|c|}{ By years of experience (\%) } & \multicolumn{3}{|c|}{ By job title (\%) } & \multicolumn{4}{|c|}{ By nature of role $(\%)$} & \multicolumn{4}{|c|}{ By qualification (\%) } \\
\hline & $1-5$ & $6-10$ & $>10$ & Sig. & EN & RN & Sig. & C & M & E & Sig. & H & B & M & Sig. \\
\hline $12 a$ & 30.4 & 15.7 & 29.1 & 0.025 & 43.8 & 19.3 & $<0.001$ & 26.1 & 30.8 & 27.8 & NS & 32.9 & 24.2 & 24.5 & NS \\
\hline $12 b-i$ & 43.9 & 23.6 & 35.5 & 0.001 & 56.1 & 29.8 & 0.001 & 36.8 & 43.6 & 27.8 & NS & 46.6 & 36.8 & 29.4 & 0.015 \\
\hline $12 b-i i$ & 61.4 & 44.8 & 41.9 & 0.009 & 63.0 & 51.0 & NS & 53.9 & 46.1 & 50.1 & NS & 59.1 & 55.1 & 44.1 & 0.038 \\
\hline $12 \mathrm{c}$ & 44.4 & 36.9 & 48.1 & NS & 49.3 & 37.5 & 0.027 & 41.3 & 51.3 & 61.1 & NS & 42.0 & 41.8 & 43.5 & NS \\
\hline $12 d-i$ & 33.9 & 18.4 & 34.1 & 0.026 & 42.5 & 25.5 & 0.029 & 30.5 & 35.9 & 16.7 & NS & 34.1 & 33.1 & 23.6 & 0.043 \\
\hline $12 d-i i$ & 22.8 & 21.0 & 35.5 & 0.040 & 28.8 & 20.8 & 0.043 & 23.4 & 41.0 & 22.2 & NS & 21.6 & 28.0 & 25.4 & NS \\
\hline 12d-iii & 27.4 & 22.4 & 34.1 & 0.045 & 35.6 & 22.4 & 0.024 & 26.8 & 38.5 & 22.3 & NS & 23.8 & 33.1 & 24.5 & NS \\
\hline $12 \mathrm{e}$ & 29.3 & 18.4 & 36.7 & NS & 38.3 & 22.9 & 0.020 & 27.6 & 38.5 & 22.3 & NS & 29.6 & 28.6 & 27.4 & NS \\
\hline $12 f-i$ & 44.4 & 32.9 & 53.1 & 0.007 & 52.0 & 35.9 & 0.002 & 40.8 & 53.8 & 66.7 & 0.031 & 45.5 & 41.2 & 46.1 & NS \\
\hline 12f-ii & 45.6 & 31.5 & 57.0 & 0.006 & 52.1 & 36.5 & $<0.001$ & 41.2 & 59.0 & 72.2 & 0.005 & 44.3 & 44.1 & 47.1 & NS \\
\hline $12 g$ & 59.1 & 47.4 & 63.3 & NS & 63.0 & 52.1 & 0.023 & 55.4 & 64.1 & 72.2 & NS & 61.4 & 53.8 & 58.8 & NS \\
\hline $12 \mathrm{~h}-\mathrm{i}$ & 40.3 & 34.2 & 37.9 & NS & 46.6 & 33.9 & NS & 37.8 & 46.2 & 27.8 & NS & 44.3 & 36.0 & 36.3 & NS \\
\hline $12 \mathrm{~h}-\mathrm{ii}$ & 31.6 & 25.0 & 27.8 & NS & 41.1 & 23.4 & 0.005 & 29.0 & 35.9 & 16.7 & NS & 37.5 & 25.7 & 26.5 & 0.049 \\
\hline $12 \mathrm{i}$ & 32.8 & 27.6 & 44.3 & NS & 42.4 & 27.0 & 0.017 & 32.0 & 53.8 & 27.8 & NS & 36.4 & 32.3 & 35.2 & NS \\
\hline
\end{tabular}

*Percentage only includes extent of contribution $>=40 \%$

$+\mathrm{NS}=$ Not significant

\#By role nature: $\mathrm{C}=$ Clinician, $\mathrm{M}=$ Management and $\mathrm{E}=$ Education

§By qualification: $\mathrm{H}=$ Higher Diploma, $\mathrm{B}=$ Bachelor's degree and $\mathrm{M}=$ Master's degree or higher

\section{Sustainable development of UHC for elderly healthcare services: Nurses' importance}

Table 5 showed nurses' perceived importance to the sustainable development of UHC for elderly healthcare services. In general, those with 6-10 years of experience, RNs, in management and with a master's degree or higher showed significantly higher perceived contribution. Those in education showed the lowest perceived contribution in all aspects.

Table 5 - Percentage of nurses' perceived importance to sustainable UHC for elderly healthcare services. Hong Kong, 2015

\begin{tabular}{|c|c|c|c|c|c|c|c|c|c|c|c|c|c|c|c|}
\hline \multirow{2}{*}{ Question } & \multicolumn{4}{|c|}{ By years of experience (\%) } & \multicolumn{3}{|c|}{ By job title (\%) } & \multicolumn{4}{|c|}{ By nature of role $(\%)$} & \multicolumn{4}{|c|}{ By qualification (\%) } \\
\hline & $1-5$ & $6-10$ & $>10$ & Sig. & EN & RN & Sig. & C & M & $E$ & Sig. & $\mathrm{H}$ & B & M & Sig. \\
\hline $13 a$. & 79.5 & 84.2 & 86.1 & NS & 71.2 & 85.4 & 0.022 & 81.8 & 94.9 & 61.1 & 0.027 & 73.8 & 88.2 & 81.4 & NS \\
\hline 13b-i. & 84.2 & 93.5 & 91.1 & 0.009 & 80.9 & 89.6 & NS & 87.3 & 94.9 & 83.3 & NS & 85.3 & 86.8 & 92.2 & NS \\
\hline 13b-ii. & 86.6 & 97.4 & 92.4 & NS & 86.3 & 92.2 & NS & 90.7 & 92.3 & 83.3 & NS & 87.5 & 89.7 & 94.1 & NS \\
\hline $13 c$. & 85.4 & 98.7 & 93.7 & $<0.001$ & 82.2 & 93.2 & NS & 90.4 & 94.8 & 83.4 & NS & 85.2 & 90.4 & 95.1 & 0.018 \\
\hline $13 d-i$. & 79.5 & 90.8 & 89.8 & 0.045 & 76.7 & 87.0 & NS & 84.4 & 92.3 & 72.2 & 0.032 & 80.7 & 83.1 & 90.2 & NS \\
\hline 13d-ii. & 83.0 & 93.4 & 93.6 & NS & 78.1 & 91.2 & 0.028 & 87.7 & 94.9 & 77.7 & 0.005 & 81.8 & 87.5 & 94.1 & NS \\
\hline 13d-iii. & 81.3 & 93.4 & 91.2 & NS & 79.4 & 88.0 & NS & 85.9 & 92.3 & 83.3 & NS & 83.0 & 83.1 & 94.1 & NS \\
\hline $13 e$. & 81.3 & 92.1 & 88.6 & NS & 78.1 & 88.5 & 0.035 & 85.9 & 89.7 & 72.2 & 0.023 & 80.7 & 86.1 & 89.2 & 0.027 \\
\hline $13 f-i$. & 83.0 & 90.8 & 88.6 & NS & 82.2 & 88.1 & NS & 86.6 & 87.1 & 77.7 & NS & 84.1 & 86.0 & 88.3 & NS \\
\hline $13 f-i i$. & 85.4 & 96.0 & 89.9 & 0.030 & 82.2 & 92.2 & NS & 89.6 & 89.7 & 77.7 & NS & 85.2 & 89.0 & 92.2 & NS \\
\hline $13 \mathrm{~g}$. & 86.6 & 96.0 & 92.4 & 0.029 & 82.1 & 94.3 & NS & 91.1 & 89.7 & 77.8 & NS & 87.5 & 91.1 & 91.2 & NS \\
\hline 13h-i. & 78.4 & 90.7 & 84.8 & 0.013 & 78.1 & 84.9 & NS & 83.3 & 87.2 & 66.7 & NS & 76.1 & 83.9 & 87.2 & NS \\
\hline 13h-ii. & 83.0 & 90.8 & 83.5 & NS & 80.8 & 88.0 & 0.027 & 86.2 & 82.0 & 72.2 & 0.031 & 84.1 & 85.3 & 85.3 & NS \\
\hline $13 i$. & 83.7 & 88.2 & 88.6 & NS & 79.4 & 89.6 & 0.005 & 87.0 & 87.2 & 66.7 & 0.012 & 80.7 & 89.0 & 86.3 & NS \\
\hline
\end{tabular}

*Percentage only includes important and very important

$+\mathrm{NS}=$ Not significant

¥By nature of role: $\mathrm{C}=$ Clinician, $\mathrm{M}=$ Management and $\mathrm{E}=$ Education

§By qualification: $\mathrm{H}=$ Higher Diploma, $\mathrm{B}=$ Bachelor's degree, and $\mathrm{M}=$ Master's degree or higher

\section{Discussion}

The respondents' knowledge of UHC for elderly healthcare services was fairly satisfactory. Those who were in clinical and management positions perceived themselves as having more contribution and importance in UHC implementation in comparison with the responses by the educators. Nurses were relatively indifferent to healthcare policy and politics. Possible explanations and implications will be discussed below. 


\section{Inclusiveness of UHC for elderly healthcare services}

In general, significantly more respondents incorrectly identified that we had an independent and separate drug-dispensing system in Hong Kong. They were those who had less years of experience, were ENs, in clinical practice, and held a diploma qualification. Similar findings were found in healthcare financing for tertiary care. Conversely, for healthcare financing in primary care, those with bachelor's degrees showed significantly lower level of knowledge of its source of funding. A separated drug-dispensing system has been debated in Hong Kong for over two decades, and its advocates have encountered enormous resistance from the medical profession. The low level of knowledge of this among nurses implies their remoteness from public affairs and policy in general. On the other hand, ENs were more aware of the existence of licensed elderly care workers than the RNs. Universal health coverage for elderly healthcare services has significant implications to our healthcare system. As our population ages, one in every three citizens in 2041 will be elderly ${ }^{(15)}$. The demand for healthcare services will increase. To meet the escalating demand, the government needs to allocate additional resources, be they human or financial, to prepare the society. The RNs constitutes the major nursing workforce in Hong Kong. There is no reason for RNs to have such low level knowledge and to be unprepared for this forthcoming challenge.

\section{Sustainable development of UHC for elderly healthcare services}

This study revealed that nurses showed low political involvement and powerlessness in the process of policy making, which was consistent with the findings from previous studies ${ }^{(7,16-18)}$. Focusing on the difference between RNs and ENs, $88.5 \%$ of the former believed that it was important for nurses to develop evidence-based policy for managing the nursing workforce, while only $78.1 \%$ of the latter agreed that it was the nurse's role. This may reflect the importance of training and education in fostering nurses' political sense, particularly their understanding of the policy making process. From the core competencies stipulated by The Nursing Council of Hong Kong, ENs are only required to practice in accordance with policies, ${ }^{(19)}$ while RNs are expected to understand the process of developing health care policies. However, only 15 hours were suggested for teaching health care policies in the curriculum for nursing education ${ }^{(20)}$. The inadequacy of policy studies in nursing education can be reflected in the answers of the respondents to the questions about the perceived contribution to evidence- based policy making. Only $38.3 \%$ and $22.9 \%$ of ENs and RNs, respectively, claimed that they had more than a $40 \%$ contribution in the development of evidence-based policy. This finding suggests that the majority of nurses feel powerless and remote from policy-making related to healthcare services. As a result, they are indifferent to the political process leading to UHC for elderly healthcare services in Hong Kong. This phenomenon warrants the immediate attention of the nursing profession. It may be timely and appropriate to reconsider the long standing suggestion to incorporate political education in the education of nurses ${ }^{(7,16-18)}$.

From the findings of this study, nurses with higher academic qualifications, such as the master's degree and higher, perceived a significantly higher level of importance in helping to develop/strengthen policies to improve the quality of nursing education. In recent years, the Government has proposed several major changes in elderly care policy in response to the challenges evolving from our rapidly aging society, such as strengthening primary care, emphasizing aging in place, and a voluntary health insurance scheme. Understandably, these changes mean increasing demand for both RNs and ENs at the community level. The question is: will nurses be able to meet the demand, or an even better question may be, have nurses been prepared for it? Unfortunately, with the present RN and EN mix, the answer is negative. The findings of this study reaffirmed this. It is crucial, therefore, to involve nurses in policy-making, particularly when a major change is expected to occur. To ensure nurses are competent in the political process, the professional body such as The Nursing Council of Hong Kong should consider revising the indicated nursing curriculum and core-competency of ENs and RNs to strengthen the nurses' knowledge and ability to participate in policy development. Thus, the gap between policy and practice could be bridged.

Despite the leading role of nursing education in Asia, surprisingly, nurse educators perceived relatively low importance of nurses' contribution to healthcare services for the elderly in Hong Kong, as compared to their counterparts in clinical practice and management. It may imply that nurse educators felt that they had minimal power in affecting the healthcare system and policy-making in Hong Kong. Another possible explanation may be that this is due to the low involvement of nurse educators in setting policy and, needless to say, the political agenda(21) Nurse educators may only have a chance to voice their view if there is an interest group or a public consultation. Since nurse educators are responsible for nurturing the future generation of nurses, they should be role models for their students, and should equip themselves 
well in this area. There is an urgent need to involve more nurse educators in the political process leading to decision-making(22).

The survey uncovered a considerable knowledge gap in nurses' knowledge of UHC in elderly care services, but care must be taken in interpreting the findings from such a nonrandom sample. Having collected the data on nurses' perceived contribution and importance to policy-making across clinical, management and education sectors, the research team believes that, with the increase of the aged population, nurses could do more to enhance their capacity at various fronts to support the government's initiatives to provide UHC for elderly healthcare services(23).

\section{Conclusion}

Universal health care evolves from the 'Health for All' movement advocated by the WHO in the 1970s. Since then, the Hong Kong government has launched many initiatives in order to achieve UHC, particularly for inclusive and sustainable elderly healthcare services. Although the outcomes of these initiatives are yet to be seen, the research team considered it to be appropriate to conduct the reported survey to identify nurses' knowledge of and involvement in the process, including policy-making and implementation. It was hoped that the findings would inform major stakeholders of some issues which may possibly affect the success of these initiatives.

The survey has revealed some knowledge gaps among nurses. Their knowledge of healthcare financing, including health insurance, drug-dispensing, and human resource policy needs to be enhanced. The low perceived importance and contribution to the sustainable development of elderly healthcare services are deterrents to their possible involvement in the initiatives. After all, nurses constitute a major work force in healthcare. They should be better prepared to participate with policy-making knowledge for the benefit of the population that they serve.

\section{References}

1. Sachs JD. High stakes at the UN on the Sustainable Development Goals. Lancet. 2013 Sep 21;382(9897):1001-2.

2. WHO. WHO Global Forum for Government Chief Nursing and Midwifery Officers, 14-15 May 2014, Geneva, Switzerland: Nursing and Midwifery Workforce and Universal Health Coverage. Forum Statement [Internet]. 2014 May [updated 2014 May]; [Acesso 1 jul 2015]; Disponível em: http://www.who.int/hrh/ events/global_forum_chiefnursing/en/
3. WHO. Universal health coverage (UHC). [Internet]. 2014 Sep [updated 2014 Sep]; ; [Acesso 1 jul 2015]; Disponível em: http://www.who.int/mediacentre/ factsheets/fs395/en/http://www.who.int/mediacentre/ factsheets/fs395/en/

4. Department of Health. Major Health Indicators [Internet]. 2015 [updated 2015 Jul 6]; ; [Acesso 9 jul 2015]; Disponível em: http://www.healthyhk.gov.hk/ phisweb/en/healthy_facts/health_indicators/

5. Food and Health Bureau $(\mathrm{CH})$. Consultation document on voluntary health insurance scheme. Hong Kong: Food and Health Bureau; 2014 Dec. 193 p. http:// www.vhis.gov.hk/doc/en/full_consultation_document/ consultation_full_eng.pdf

6. Chan SWC, Cheng BS. Political participation in Hong Kong: A study. J Nurs Manage. 1999 Feb 18;7:167-75. 7. Boswell C, Cannon S, Miller J. Nurses' political involvement: Responsibility versus privilege. J Prof Nurs. 2005 Jan-Feb;21(1):5-8. doi:10.1016/j. profnurs.2004.11.005.

8. Willmann $\mathrm{JH}$. Advocating for nursing through public policy. Perioper Nurs Clin. 2012 Nov 13;7(4):367-74.

9. Woodward B, Smart D, Benavides-Vaello S. Modifable factors that support political participation by nurses. J Prof Nurs. 2015 Jun 16, Forthcoming.

10. Legislative Council. LCQ21: Residential care homes for the elderly [Internet]. 2013 Jun 26 [updated 2013 Jun 26]; [Acesso 9 jul 2015]; Disponível em: http://www.info.gov.hk/ gia/general/201306/26/P201306250600.htmhttp://www. legco.gov.hk/research-publications/english/1415rb01preparing-for-population-ageing-20141113-e.pdf

11. Leung JLM, Sezto NW, Chan WC, Cheng SP, Tang SH Lam LCW. Attitudes and perceived competence of residential care homes staff about dementia care. Asian J Gerontol Geriatr. 2013 Jun;8(1):21-9.

12. The Government of Hong Kong Special Administrative Region. The 2014 Policy Address: Support the Needy, Let Youth Flourish Unleash Hong Kong's Potential [Internet]. Hong Kong: Government of Hong Kong Special Administrative Region; 2014. Chapter 4: Medical Services, Public Health and Elderly Care. [Acesso 9 jul 2015]. Disponível em: http://www.policyaddress.gov. hk/2014/eng/pdf/Agenda_Ch4.pdf

13. Hulme D. The Millennium Development Goals (MDGs): A short history of the world's biggest promise. [Internet]. Manchester: University of Manchester; 2009 Sep. [Acesso em 9 jul 2015]. Disponível em: http:// www.bwpi.manchester.ac.uk/medialibrary/publications/ working_papers/bwpi-wp-10009.pdf

14. The Nursing Council of Hong Kong. Statistics and Lists of Nurses [Internet]. 2015 [updated 2015]; [Acesso 1 jul 2015]. Disponível em: http://www.nchk.org.hk/en/ statistics_and_lists_of_nurses/statistics/index.html 
15. Legislative Council Secretariat. Preparing the population ageing. Hong Kong: Legislative Council Secretariat; 2014 Nov 13. 14 p.

16. Conger $\mathrm{CO}$, Johnson $\mathrm{P}$. Integrating political involvement and nursing education. Nurse Educ. 2000 Mar/Apr;25(2):99-103.

17. Des Jardin KE. Political Involvement in NursingEducation and Empowerment. AORN J. 2001 Oct;74(4):467-75.

18. Des Jardin KE. Political Involvement in NursingPolitics, Ethics, and Strategic Action. AORN J. 2001 Nov; 74(5):613-22.

19. Nursing Council of Hong Kong (CH). Corecompetencies for enrolled nurses (general) and a reference guide to the syllabus of subjects and requirements for the preparation of enrolled nurse (general) in the Hong Kong Special Administrative Region. Hong Kong: Nursing Council of Hong Kong; 2014 Dec. 30 p.

20. Nursing Council of Hong Kong $(\mathrm{CH})$. A reference guide to the syllabus of subjects and requirements for the preparation of registered nurse (general) in the Hong Kong Special Administrative Region. Hong Kong: The Nursing Council of Hong Kong; 2014 Dec. 39 p.

21. Miethe C. A description and critical review of the policy-making process in Hong Kong. Hong Kong: Hong Kong Democratic Foundation; 2007 Nov. 24 p.

22. Heller BR, Oros MT, Durney-Crowley J. The future of nursing education: ten trends to watch. Nurs Health Care Perspec. 2000 Jan-Feb;21(1):9-13.

23. Ross F, Marks-Maran D, Tye C. A foot in two camps: An exploratory study of nurse leaders in universities. Nurse Educ Today. 2013 Mar;33(11):1342-6. Creative Commons (CC BY).

This license lets others distribute, remix, tweak, and build upon your work, even commercially, as long as they credit you for the original creation. This is the most accommodating of licenses offered. Recommended for maximum dissemination and use of licensed materials. 